\title{
Inital experience of imaging cardiac sarcoidosis using hybrid PET-MR - a technologist's case study
}

\author{
From 16th Annual SCMR Scientific Sessions \\ San Francisco, CA, USA. 31 January - 3 February 2013
}

Celia O'Meara ${ }^{1 *}$, Leon J Menezes ${ }^{1}$, Steven K White ${ }^{2}$, Eleanor Wicks ${ }^{2}$, Perry Elliott ${ }^{2}$

\section{Background}

Cardiac imaging has been identified as a potential use of hybrid PET-MRI. This new technology allows simultaneous Positron Emission Tomography (PET) and MR scanning to occur.

This case study features a 34 year old male with known pulmonary sarcoidosis which was diagnosed in 2006 and initially treated with immunosuppressants. He presented with NYHA functional class 2 symptoms. ECHO showed asymmetrical LV anterior and lateral wall hypertrophy with a maximum wall thickness of $18 \mathrm{~mm}$ in the basal and mid anterior and lateral wall.

The patient was referred for a cardiac18F Fluorodeoxyglucose (FDG) PET-MR study to determine the cause of the hypertrophy. The possible differential diagnoses included hypertrophic cardiac myopathy with pulmonary sarcoidosis or cardiac sarcoidosis.

\section{Methods}

Prior to the scan, the patient followed a high protein, low carbohydrate diet for one day. This was then followed by a 12 hour fast to suppress physiologic glucose metabolism by the heart.

The patient was administered with $355 \mathrm{mBq}$ of $18 \mathrm{~F}$ FDG 180 minutes prior to the PET-MR study.
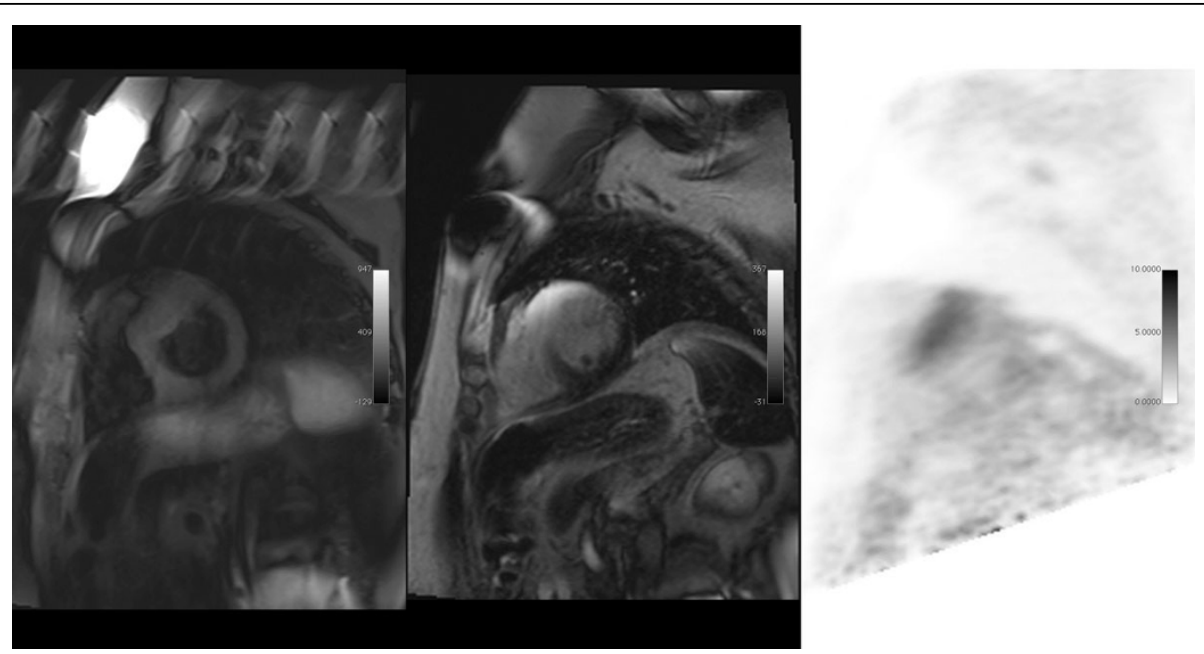

Figure 1 From left to right: 1) SA STIR demonstrating shows homogeneous signal from the LV myocardium. 2) SA LGE demonstrating focal mid myocardial wall LGE in the antero-septal segments. 3) SA 18F FDG PET showing focal uptake in the antero-septal segements Note is made of a Reveal device visualsied on images 1 \& 2 .

$\overline{1}$ Institute of Nuclear Medicine, University College London Hospitals, London,

UK

Full list of author information is available at the end of the article

() 2013 O'Meara et al; licensee BioMed Central Ltd. This is an Open Access article distributed under the terms of the Creative Commons 


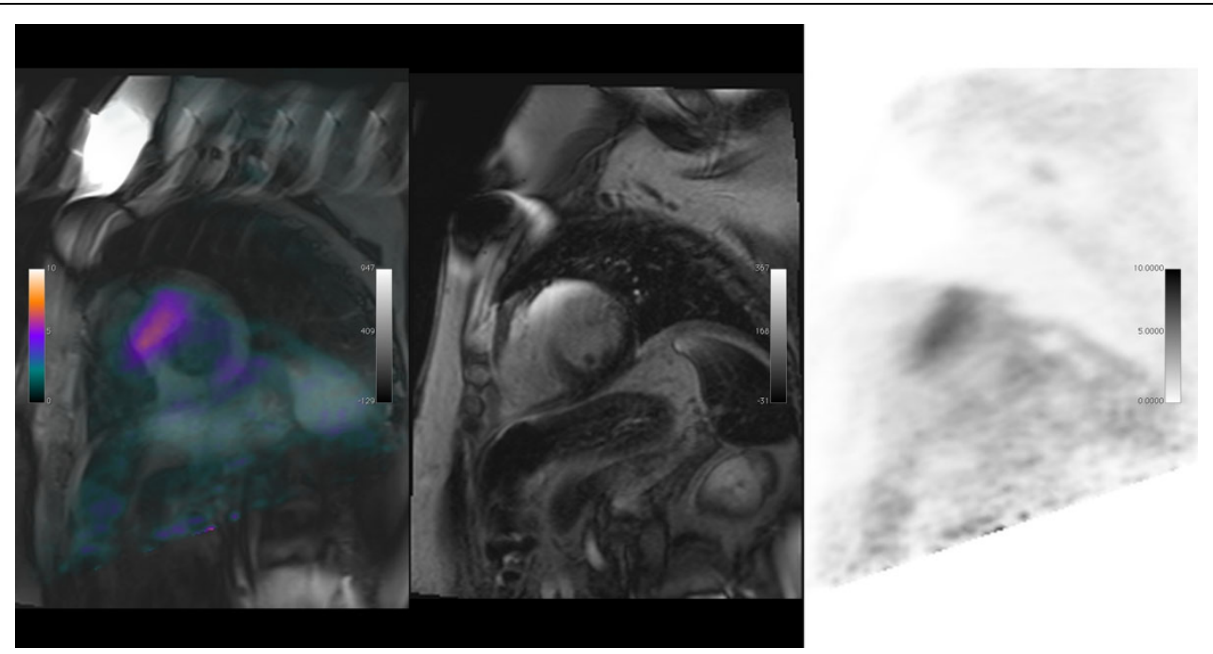

Figure 2 These images show the fusion of the PET onto the STIR sequence, demonstrating the area of active inflammation despite there being no oedema.

A simultaneous PET-MR study was acquired. A standard CMR protocol was undertaken in conjunction with a simultaneous 10 minute single PET bed using a Siemens Biograph mMR hybrid PET-MR scanner. This is a $3 \mathrm{~T}$ magnet containing a $260 \mathrm{~mm}$ field of view PET detector located at the isocentre.

\section{Results}

The scan demonstrated mediastinal 18F FDG avid lymphadenopathy with anterio-lateral myocardial thickening with mid-myocardial LGE and focal 18F FDG uptake compatible with active myocardial inflammation within an area of "scar" in keeping with active cardiac sarcoidosis.

The oedema sensitive STIR sequence did not differentiate between the hyper-metabolic active disease and the chronic "burnt out" disease.

\section{Conclusions}

This patient is one of the first examples of imaging active cardiac sarcoidosis using a hybrid PET-MR technique. It demonstrates the potential for differentiating between active and chronic cardiac sarcoidosis during one scan. This new imaging technique could have a substantial impact on the diagnosis and management of cardiac sarcoidosis

\section{Funding}

UCLIUCLH receives a proportion of funding from the Department of Health's NIHR Biomedical Research Centres funding scheme.

\footnotetext{
Author details

${ }^{1}$ Institute of Nuclear Medicine, University College London Hospitals, London, UK. ${ }^{2}$ Heart Imaging Centre, Heart Hospital, UCLH, London, UK.
}

Published: 30 January 2013

\section{doi:10.1186/1532-429X-15-S1-T1}

Cite this article as: O'Meara et al.: Inital experience of imaging cardiac sarcoidosis using hybrid PET-MR - a technologist's case study. Journal of Cardiovascular Magnetic Resonance 2013 15(Suppl 1):T1.

\section{Submit your next manuscript to BioMed Central} and take full advantage of:

- Convenient online submission

- Thorough peer review

- No space constraints or color figure charges

- Immediate publication on acceptance

- Inclusion in PubMed, CAS, Scopus and Google Scholar

- Research which is freely available for redistribution 